\title{
Statement of Retraction
}

\author{
Statement of Retraction. Gerolama Condorelli, Giovanni Vigliotta, Alessandra Trencia, Maria Alessandra Maitan, \\ Matilde Caruso, Claudia Miele, Francesco Oriente, Stefania Santopietro, Pietro Formisano, and Francesco Beguinot. \\ Protein Kinase C (PKC)- $\alpha$ Activation Inhibits PKC- $\zeta$ and Mediates the Action of PED/PEA-15 on Glucose Transport in \\ the L6 Skeletal Muscle Cells. Diabetes 2001;50:1244-1252. DOI: 10.2337/diabetes.50.6.1244. PMID: 11375323
}

American Diabetes Association

https://doi.org/10.2337/db19-rt02b

The above-cited article has been retracted by the American Diabetes Association (ADA), the publisher of Diabetes. This article was previously the subject of an expression of concern in the February 2018 issue of the journal (Diabetes 2018;67:345. DOI: 10.2337/db17ec2017b. PMID: 29109245)

On November 6, 2017, ADA contacted the corresponding author's institution, Università degli Studi di Napoli Federico II (Naples, Italy), to request an investigation into the possible duplication of several images presented in this article. These instances include the following:

- In Fig. 2, lanes 2 and 4 appear to be duplicates.

- Figure 6 appears to contain the following potentially duplicated images:

○ In the "Total Glut 4" strip, lanes 2, 3, 6, and 7 appear to be duplicates. Likewise, lanes 4 and 8 appear to be duplicates.

○ In the "P.M. Glut 1" strip, lanes 5 and 7 appear to be duplicates. Lane 3 appears to be a duplicate of lane 8 , with horizontal rotation.

- The "Total Glut 1" strip of Fig. 6 appears to have been previously published, with contrast and sharpness adjustments, as lanes 3-9 of the IR strip in Fig. 5A of the following article:

○ Caruso et al. J Biol Chem 1999;274:28637-28644. DOI: https://doi.org/ 10.1074/jbc.274.40.28637. PMID: 10497232

- In Fig. $8 B$, lanes 3 and 4 appear to be duplicates.

In March 2018, the University informed ADA that a three-person committee had been appointed to investigate the issues cited above, but since then the University has not responded to requests for information on the status of the investigation. Therefore, ADA's Panel on Ethical Scientific Programs (ESP) has independently reviewed these issues. The ESP determined that the concerns cited above are valid and that these apparent instances of image duplication compromise the overall reliability of the study. ADA has chosen to retract this publication on the basis of the ESP's assessment.

Diabetes is a member journal of the Committee on Publication Ethics (COPE) (publicationethics.org). As such, the editors of the journal and the ESP refer to COPE's guidelines and recommendations when reviewing such matters. 